\title{
The effect of bed rest and an exercise countermeasure on leg venous function
}

\author{
Noortje T. L. van Duijnhoven - Michiel W. P. Bleeker · Patricia C. E. de Groot • \\ Dick H. J. Thijssen · Dieter Felsenberg · Jörn Rittweger · Maria T. E. Hopman
}

Accepted: 6 August 2008/Published online: 22 August 2008

(c) The Author(s) 2008. This article is published with open access at Springerlink.com

\begin{abstract}
This study was performed to assess the effect of resistive vibration exercise during bed rest deconditioning on venous vascular dimension and function, as measured with ultrasound in the popliteal vein. Sixteen men were assigned to bed rest (BR-Ctrl) or bed rest with resistive vibration exercise (BR-RVE). Before and at 25 and 52 days of bed rest, popliteal vein diameter was measured at increasing cuff pressures. Venous capacitance and compliance were calculated from the pressure-volume curve. After 52 days of bed rest, BR-Ctrl showed no change in baseline popliteal vein diameter or compliance,
\end{abstract}

N. T. L. van Duijnhoven - M. W. P. Bleeker .

P. C. E. de Groot · D. H. J. Thijssen - M. T. E. Hopman ( $)$

Department of Physiology 143,

Radboud University Nijmegen Medical Centre,

Geert Grooteplein-noord 21, 6525 EZ Nijmegen,

The Netherlands

e-mail: m.hopman@fysiol.umcn.nl

N. T. L. van Duijnhoven

e-mail: n.vanduijnhoven@fysiol.umcn.nl

M. W. P. Bleeker

Department of Internal Medicine, Bernhoven Hospital,

Veghel, The Netherlands

D. H. J. Thijssen

Research Institute for Sports and Exercise Science,

Liverpool Moores University, Liverpool, UK

D. Felsenberg

Center for Muscle and Bone Research, Charité-Campus

Benjamin Franklin, Free University and Humboldt University

Berlin, Berlin, Germany

J. Rittweger

Institute for Biophysical and Clinical Research into Human

Movement, Manchester Metropolitan University, Alsager, UK while venous capacitance decreased. Resistive vibration exercise had no effect on the response in venous diameter, capacitance or compliance to 52 days of bed rest. The decline in venous capacitance due to long-term bed rest is not effectively counteracted by resistive vibration exercise, indicating that an alternative factor during bed rest deconditioning is responsible for venous changes.

Keywords Bed rest deconditioning - Ultrasound . Venous capacitance $\cdot$ Venous compliance

\section{Introduction}

Venous hemodynamics play an essential role in cardiovascular homeostasis and are critical in determining venous return and thus cardiac filling and stroke volume (Rothe 1986). Physical activity and deconditioning substantially affect cardiovascular homeostasis, influencing parameters such as venous capacitance and compliance. Venous capacitance reflects the blood volume that is stored in the venous vascular system. This stored venous volume can be used to increase venous return to the heart when necessary, but excessive venous pooling during standing may also cause orthostatic intolerance. Venous compliance represents the change in volume of the veins in response to a change in pressure. Both venous capacitance and compliance are major determinants in the vital functions of the venous system, and a numerous amount of studies have been performed to specify their role in orthostatic intolerance after bed rest and space flight in humans. To study the effect of physical deconditioning on the venous vascular system, several human deconditioning models have been used, such as leg immobilisation (Bleeker et al. 2005a), space flight (Arbeille et al. 2001; Fomina and Kotovskaia 
2005; Watenpaugh et al. 2001), bed rest (Arbeille et al. 1999, 2001; Belin de Chantemele et al. 2004; Bleeker et al. 2005b; Bonde-Petersen et al. 1994; Buckey et al. 1992; Christ et al. 2001; Convertino et al. 1989; Louisy et al. 1997; Melchior and Fortney 1993; Xiao et al. 2005) and spinal-cord injury (Frieden et al. 1987; Hopman et al. 1994; Wecht et al. 2000). Sparse data on venous diameter show a reduction in cross-sectional area of femoral venous diameter after bed rest (Arbeille et al. 1999, 2001), but no change in tibial and gastrocnemial venous diameter (Belin de Chantemele et al. 2004). Although inconsistent results are reported, the leading thought is that deconditioning causes an increase in venous compliance, which is mainly attributed to atrophy of the surrounding muscles.

When using venous occlusion plethysmography, whole calf or limb compliance is assessed (Brakkee and Kuiper 1982; Pointel et al. 1981; Wilkinson and Webb 2001), implicating a possible overestimation of venous compliance. To avoid the influence of muscle tissue on the measurement, our lab demonstrated that ultrasound as a suitable and reproducible method to examine compliance of a major conduit vein, i.e. the popliteal vein (De Groot et al. 2005). Transverse echographic views were used before for measuring cross-sectional areas of the deep and muscular vein in the calf (Belin de Chantemele et al. 2004). Ultrasound and plethysmography measurements of venous compliance correlated significantly (De Groot et al. 2005) and supported the observation by Buckey et al. (1988), who reported that most volume changes at different venous occlusion pressures are attributable to deep venous filling which is represented by the popliteal vein.

A major preventative measure to offset deconditioning effects of microgravity on maximal aerobic capacity, musculoskeletal structure and orthostatic function is physical exercise (Convertino 1996). Applied during bed rest, training in the modality of resistive vibration exercise has been shown to attenuate the reduction in arterial vascular dimension and function (Bleeker et al. 2005b). However, an efficient countermeasure effect of this physical exercise during deconditioning on the venous vascular system is not demonstrated yet. Resistive exercise failed to affect the response of tibial and gastrocnemial vein diameter to bed rest (Belin de Chantemele et al. 2004). If vein diameter accounts for venous capacitance and compliance, and resistive vibration exercise is no effective countermeasure on a relatively spacious vein (not directly surrounded by muscle mass), it is unlikely that exercise has a protective effect on venous function. The purpose of the present study was to assess the effect of horizontal bed rest deconditioning and the countermeasure resistive vibration exercise on venous vascular dimension and function of the popliteal vein as measured with ultrasound. We hypothesized that venous vascular dimension and function will be reduced by bed rest deconditioning and that these changes will not be counteracted by resistive vibration exercise.

\section{Methods}

Subjects

Sixteen healthy men (age $34 \pm 2$ years) participated in the Berlin Bed Rest study. Subjects were randomly assigned to bed rest (BR-Ctrl) or bed rest with resistive vibration exercise (BR-RVE). Subject characteristics are presented in Table 1. All subjects were screened using a medical history and physical examination and did not have any medical problems. None of them suffered from diabetes or cardiovascular disease or used any medication. Smoking was not used as an exclusion criterion, but was prohibited during the bed rest trial. All subjects gave their written, informed consent. Before participation, the Ethics Committee of the Medical School of the Free University Berlin had approved the Berlin Bed Rest study.

\section{Procedures}

The vascular characteristics of all subjects were measured before, and at 25 and 52 days of bed rest deconditioning (pre-, day 25 and day 52, respectively).

\section{Bed rest protocol}

After the initial series of experiments, subjects were placed at complete horizontal bed rest. All personal hygiene activities were performed in the supine position. Subjects were housed in a dedicated clinical ward of the University Hospital Benjamin Franklin and were continuously

Table 1 Subject characteristics

\begin{tabular}{lcc}
\hline & BR-Ctrl & BR-RVE \\
\hline Number & 8 & 8 \\
Age (years) & $35 \pm 7$ & $33 \pm 6$ \\
Body mass (kg) & $76 \pm 5$ & $80 \pm 11$ \\
Height (cm) & $182 \pm 6$ & $184 \pm 9$ \\
Systolic blood pressure (mmHg) & $118 \pm 6$ & $119 \pm 13$ \\
Diastolic blood pressure (mmHg) & $73 \pm 8$ & $75 \pm 8$ \\
Heart rate in rest (beats/min) & $67 \pm 6$ & $68 \pm 8$ \\
Exercise (h/week) & $2.9 \pm 3.9$ & $3.1 \pm 2.3$ \\
Smokers & 4 & 3 \\
\hline
\end{tabular}

Data are represented as means $\pm \mathrm{SD}$

Smokers smoked 6 months prior to the study

$B R$ - $C t r l$ bed rest group, $B R-R V E$ bed rest group with resistive vibration exercise 
monitored with video cameras to guarantee compliance with the bed rest protocol. In addition, the monitoring with force transducers of the vertical forces generated by the subjects controlled strict bed rest and avoidance of powerful movements. The diet of the subjects was controlled carefully.

\section{Resistive vibration exercise}

Subjects in the BR-RVE group were exposed to two daily sessions of resistive vibration exercise; one in the morning and one in the afternoon ( $8 \mathrm{~min}$ pure exercise time per session), with the exception of Sundays and Wednesday afternoons. Exercise was performed on a specific vibration system that was developed for application under microgravity and bed rest conditions (Galileo Space, Novotec, Pforzheim, Germany). The used equipment and the countermeasure exercise are previously described in detail (Bleeker et al. 2005b). In short, the training device consisted of a vibration platform, which was vertically suspended on a trolley. Subjects remained in a supine position with their feet resting on the vibration platform and with supporting belts attached to shoulders, hips and hands. In each training session, four exercises were performed in the following order: squatting, heel and toe raises and explosive squatting. During morning sessions, all exercises were performed for at least $60 \mathrm{~s}$. If subjects were able to exceed $100 \mathrm{~s}$, the vibration frequency was increased from $19 \mathrm{~Hz}$ onwards. During afternoon sessions, subjects exercised at $60-80 \%$ of the static force achieved in the morning, but performed the first three exercises for as many times as possible within $60 \mathrm{~s}$ each. Trained staff members supervised all training sessions.

\section{Experimental protocol}

Measurements were performed at the same time of day in each individual subject, and meals were identical before each measurement and for each subject on the days of the measurements. All subjects refrained from caffeine, chocolate and alcohol from midnight on. On the testing days, subjects did not perform exercise before testing. During the measurements, subjects were in the supine position, while their heels and feet rested on a foot support $23 \mathrm{~cm}$ above the examination table (De Groot et al. 2005). After instrumentation of the subjects and an acclimatisation period of at least $20 \mathrm{~min}$, two baseline images of the popliteal vein in the popliteal space were obtained with ultrasound and stored for off-line analysis. Test procedures were started with a venous occlusion of $20 \mathrm{mmHg}$, followed by subsequent cuff pressures of 40, 60 and $80 \mathrm{mmHg}$ (De Groot et al. 2005). The occlusions of 20, 40, 60 and $80 \mathrm{mmHg}$ were sustained for predefined durations of 2, 3, 4 and 5 min, respectively, and 1-min breaks between the occlusions allowed new baseline formation (De Groot et al. 2005). During the last minute of each stage, two images of the diameter of the popliteal vein were obtained with ultrasound and stored for off-line analysis.

\section{Measurements}

\section{Ultrasound}

All diameters $(\mathrm{cm})$ of the popliteal vein were measured with an ultrasound device (Megas, Esaote, Firenze, Italy) by using a 5- to 7-MHz linear transducer. Two consecutive longitudinal images of the baseline diameter and the diameters at cuff pressures of $20,40,60$, and $80 \mathrm{mmHg}$ were frozen in the end-diastolic phase of the cardiac cycle. All measurements were performed at the same anatomic location of the vein in the popliteal fossa. Three measurements were performed per diameter image, and vessel margins were defined from leading edge to leading edge (De Groot et al. 2005). Venous cross-sectional area can be calculated accurately with the diameters obtained from longitudinal images (Jeanneret et al. 2000). Because even at low venous pressure levels the shape of the vein resembles a circle (De Groot et al. 2005), the cross-sectional area of the vein at the different cuff pressures can be calculated as $\pi$ radius $^{2}$. Capacitance was calculated as the area under the venous pressure-volume (i.e. cross-sectional area) curve. Compliance was calculated according to the curvilinear model as introduced by Van Langen (2003). This model uses three parameters, i.e., venous pressure $\left(P_{0}\right)$, resting compliance $\left(C_{0}\right)$, and the stiffness constant $(k)$, and describes the curvilinear venous-pressure relationship: $C(P)=C_{0} /\left(1+k C_{0}\left(P_{1}-P_{0}\right)\right)$, where $C$ is compliance and $P$ is pressure (Van Langen 2003). Ultrasound has shown to provide reproducible measurements on the popliteal vein, with short- and long-term coefficients of variation ranging from 2 to $9 \%$ for absolute diameters and from 10 to $15 \%$ for venous compliance at the different venous pressure steps (De Groot et al. 2005).

\section{Statistical analysis}

An unpaired Student's $t$ test was applied to assess baseline differences between the BR-Ctrl and BR-RVE group for subject characteristics and baseline values. The effect of bed rest in the BR-Ctrl and BR-RVE group was examined using one-way ANOVA. Differences in the response to bed rest between BR-Ctrl and BR-RVE were tested with twoway repeated-measures ANOVA with time as within-subject factor and group as between subject factor (Statistical Package for Social Sciences 12.0, SPSS Inc., Chicago, IL, USA). The level of statistical significance was defined at 
$\alpha=0.05$. Data are presented as means \pm SEM, unless stated otherwise.

\section{Results}

Subjects

Subject's characteristics were not different between the BR-Ctrl and BR-RVE group (Table 1). During the 52 days of bed rest, the subjects in the BR-RVE group performed a total of 89 exercise sessions, with a starting vibration frequency of $19 \mathrm{~Hz}$ and a progression to 25.9 (SD 1.9) $\mathrm{Hz}$ at the end of the study (Rittweger et al. 2006). All subjects completed the study. Due to technical problems, data of one subject in the BR-RVE group could not be included in the data analysis.

\section{Venous dimension}

Baseline diameter of the popliteal vein did not significantly change after bed rest in the BR-Ctrl and BR-RVE group (Table 2). Venous diameter at increasing venous pressure showed no difference over time (Fig. 1a, b) and resistive vibration exercise had no significant effect on the response in diameter to bed rest $(P=0.93)$.

\section{Venous function}

Popliteal vein capacitance decreased significantly after bed rest in the BR-Ctrl group, but not in the BR-RVE group (Table 2; Fig. 2). The overall interaction effect after 52 days of bed rest was not significant $(P=0.09)$. Compliance of the popliteal vein was unaltered in the BR-Ctrl

Table 2 Venous diameter, capacitance and compliance before and after 25 and 52 days of bed rest

\begin{tabular}{lccl}
\hline \multicolumn{2}{c}{ Pre } & Day 25 & Day 52 \\
\hline $\begin{array}{l}\text { Diameter }(\mathrm{cm}) \\
\text { BR-Ctrl }\end{array}$ & $0.77 \pm 0.16$ & $0.72 \pm 0.13$ & $0.69 \pm 0.13$ \\
BR-RVE & $0.86 \pm 0.11$ & $0.81 \pm 0.11$ & $0.75 \pm 0.10$ \\
Capacitance & $\left(\mathrm{cm}^{2}\right)$ & & \\
BR-Ctrl & $15.12 \pm 2.16$ & $12.89 \pm 2.29^{*}$ & $11.93 \pm 0.98^{*}$ \\
BR-RVE & $13.85 \pm 2.39$ & $14.18 \pm 1.78$ & $12.66 \pm 2.32$ \\
Compliance & $\left(\mathrm{mm}^{2} / \mathrm{mmHg}\right)$ & & \\
BR-Ctrl & $0.50 \pm 0.35$ & $0.63 \pm 0.35$ & $0.71 \pm 0.30$ \\
BR-RVE & $0.66 \pm 0.44$ & $0.89 \pm 0.41$ & $0.83 \pm 0.33$ \\
\hline
\end{tabular}

Data are represented as means $\pm \mathrm{SD}$

Post hoc $* P<0.01$ compared to pre-bed rest

$B R$-Ctrl bed rest group, BR-RVE bed rest group with resistive vibration exercise a BR-Ctrl group

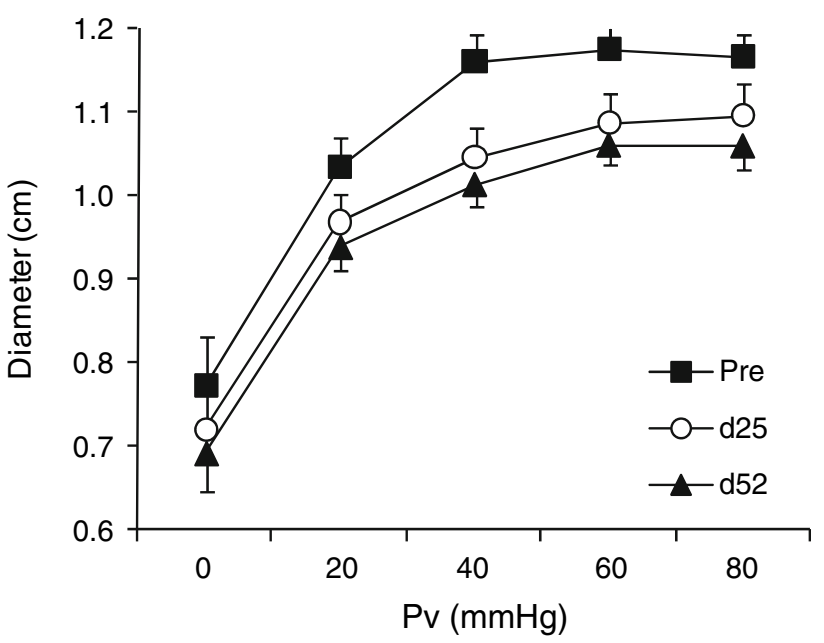

b

BR-RVE group

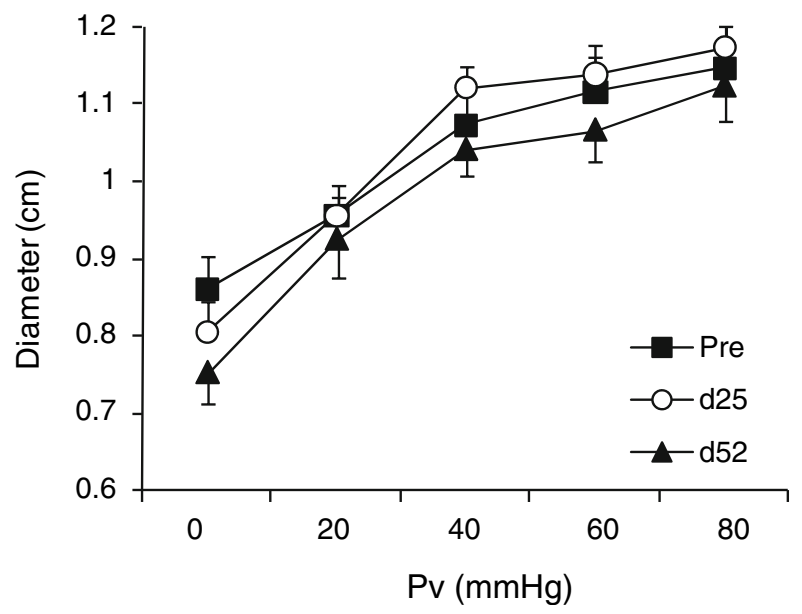

Fig. 1 a, b Diameter $(\mathrm{cm})$ of the popliteal vein at increasing venous pressure before and at 25 and 52 days of bed rest in (a) BR-Ctrl and (b) BR-RVE. BR-Ctrl, bed rest group; BR-RVE, bed rest group with resistive vibration exercise. Data are represented as means \pm SEM

and BR-RVE group (Table 2). Resistive vibration exercise had no significant effect on the response in compliance to bed rest $(P=0.63$; Fig. 3$)$.

\section{Discussion}

This study examined the effect of resistive vibration exercise during bed rest deconditioning on the dimension and function of a single leg vein. After 52 days of bed rest, venous capacitance was significantly decreased, whereas venous compliance remained unaltered. Resistive vibration exercise during bed rest deconditioning showed no countermeasure effect on the reduction in venous capacitance. 


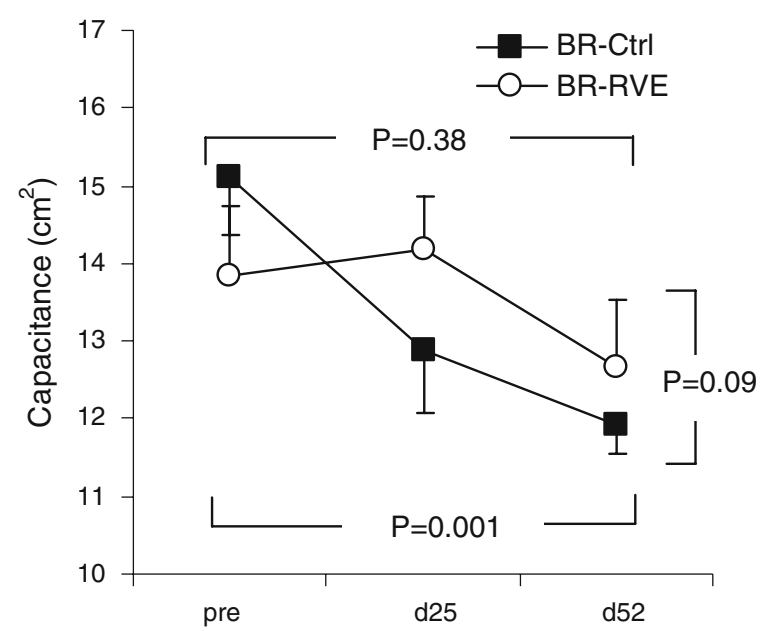

Fig. 2 Capacitance $\left(\mathrm{cm}^{2}\right)$ of the popliteal vein before and at 25 and 52 days of bed rest. BR-Ctrl, bed rest group; $B R-R V E$, bed rest group with resistive vibration exercise. Data are represented as mean$\mathrm{s} \pm$ SEM. Horizontal brackets represent the effect of bed rest in the BR-Ctrl and BR-RVE group (one-way repeated measures ANOVA); vertical brackets represent the effect of RVE (two-way repeated measures ANOVA)

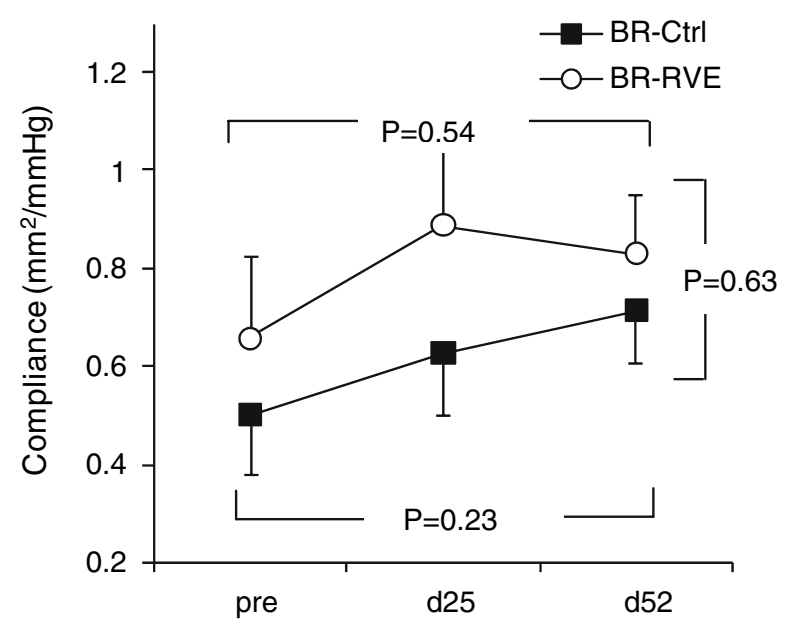

Fig. 3 Compliance $\left(\mathrm{mm}^{2} / \mathrm{mmHg}\right)$ of the popliteal vein before and at 25 and 52 days of bed rest. BR-Ctrl, bed rest group; $B R-R V E$, bed rest group with resistive vibration exercise. Data are represented as means \pm SEM. Horizontal brackets represent the effect of bed rest in the BR-Ctrl and BR-RVE group (one-way repeated measures ANOVA); vertical brackets represent the effect of RVE (two-way repeated measures ANOVA)

Bed rest and venous dimension

Despite the decreasing trend in mean values, baseline popliteal vein diameter was not significantly reduced after 52 days of bed rest. This reinforces the single finding of Belin de Chantemele et al. (2004), who reported an unaltered tibial and gastrocnemial vein diameter after 90 days of bed rest. These findings do not correspond with the previous results of a decrease in cross-sectional area of the popliteal and femoral vein (Arbeille et al. 1999, 2001) and the common result of a decreased venous volume variation after bed rest (Bleeker et al. 2004, 2005a; Christ et al. 2001; Louisy et al. 1997). The arterial vascular system also presented diameter reductions after deconditioning (Bleeker et al. 2005a, b; De Groot et al. 2006), but these changes over time were remarkably larger than previously shown in the venous vascular system. This difference in diameter response suggests that the venous and arterial vascular systems are susceptible to different stimuli, when exposed to deconditioning. As arterial adaptations were ascribed to mainly regional factors due to (the lack of) physical exercise, such as changes in blood flow and (peak) shear stress to the vessel wall (Bleeker et al. 2005b; Miyachi et al. 2001), veins might be primarily responsive to changes in pressure or blood volume (Arbeille et al. 2001).

Bed rest and venous function

Popliteal vein capacitance was significantly decreased after bed rest deconditioning, which is in agreement with several previous bed rest studies (Bleeker et al. 2004; Louisy et al. 1997). Furthermore, reductions in capacitance were reported in spinal cord-injury individuals compared to control subjects (Frieden et al. 1987; Hopman et al. 1994), which is mainly attributed to the muscle atrophy and the possible concomitant vascular atrophy in the paralyzed legs.

After bed rest, compliance of the popliteal vein remained unaltered, which is in line with previous deconditioning studies, using unilateral limb suspension (Bleeker et al. 2005a) or bed rest (Bonde-Petersen et al. 1994; Melchior and Fortney 1993). A possible reason that compliance is maintained during bed rest in the present study is the isolated location of the popliteal vein. The choice of using ultrasound to determine venous compliance was primarily based on the fact that the value of compliance is less sensitive to the influence of other than vascular factors that are changed due to bed rest (e.g. muscle mass and interstitial fluid) than when measuring whole leg compliance with plethysmography (De Groot et al. 2005). Introduced by Convertino et al. (1988), the cross-sectional area of the calf muscle would be the most dominant contributing factor to the determination of leg compliance by providing structural support to the veins to limit the expansion with increasing pressures. A decrease in muscle mass would therefore lead to an increase in venous compliance. This was confirmed by Louisy et al. (1997), who demonstrated a significant correlation between the increase in compliance and the reduction in leg volume during the first month of bed rest. In the present study, the crosssectional area of the quadriceps muscle of the leg in which 
the vascular measurements were performed was decreased by $12.9 \pm 4.7 \%(P<0.001)$ and $4.8 \pm 5.3 \%(P<0.05)$ in the BR-Ctrl and BR-RVE group, respectively (Mulder et al. 2006). Because the popliteal vein is located isolated in the popliteal space and not directly surrounded by muscles, venous compliance was not severely influenced by the decrease in muscle mass. A similar finding was reported by Belin de Chantemele et al. (2004), who found no relationship between calf muscle atrophy and calf vein deconditioning. Alternative factors that may contribute to the changes in venous compliance are alterations in the venous vessel wall (Bleeker et al. 2004; Louisy et al. 1997; Monahan et al. 2001) or gravitational gradients within the circulation (Bleeker et al. 2004). The common finding of previous investigators that compliance of total tissue (total integrated muscle and vessel tissue) increases after bed rest, may reflect that the fluid accumulation of the total tissue mass is more clinically significant than the isolated veins with regard to blood pooling during orthostatic challenges.

In this study, venous capacitance decreased after bed rest, which confirms the common idea of a reduced venous reservoir function after deconditioning. Venous compliance was maintained, indicating a sufficient vascular mechanism to transport enough blood to the heart, one of the contributing factors to prevent orthostatic intolerance after bed rest.

Resistive vibration exercise as a venous countermeasure?

Resistive vibration exercise was of no significant influence on the response in popliteal vein diameter, capacitance or compliance to 52 days of bed rest. Although the short-term response (pre-day 25) of capacitance in the exercise group was different from the control group (two-way ANOVA, $P=0.01$ ), resistive vibration exercise had no significant effect on the long-term response (pre-day 52, 2-way ANOVA, $P=0.09$ ). This might indicate a difference in time-course of capacitance response to bed rest between the control and exercise group. We hypothesize that resistive vibration exercise might prevent the rapid decline in capacitance in response to bed rest, as observed in the control group. However, in the long-term, this exercise is not sufficient to effectively counteract the decline in capacitance. As only one additional test was performed between the pre- and post-bed rest measurement, we can only speculate about a possible difference in time-course in adaptations of venous capacitance regarding the use of exercise. Considering the total period of bed rest, our data do not support a protective function of resistive vibration exercise in the long term. A recent study focusing on several other venous parameters is also lacking proof for the long-term countermeasure effect of resistive exercise during 90 days of bed rest inactivity (Belin de Chantemele et al. 2004). In both studies, the absence of exercise effect on vein response to bed rest might be ascribed to the lack of muscle mass directly surrounding the vein. On the contrary, resistive vibration exercise was previously shown to be an effective countermeasure against deterioration of the arterial dimension (Bleeker et al. 2005b), muscle mass and muscle function (Akima et al. 2003; Mulder et al. 2006), and tendon function (Kubo et al. 2004). Resistive vibration exercise is also known to increase heart rate and oxygen uptake (Rittweger et al. 2000) and blood flow (Kerschan-Schindl et al. 2001). When applying the exact same stimulus to the arterial and venous system, i.e. resistive vibration exercise, only the arterial system responds in a counteractive and protective manner. This finding corresponds with our previous suggestion that the arterial and venous vascular system require different physical triggers for adaptations to changing conditions [i.e. blood flow or (peak) shear stress versus pressure or blood volume, respectively]. However, the range of vibration frequency of the exercise has to be taken into account. A recent study reported that plantar-based vibration in the regime of $30-60 \mathrm{~Hz}$ significantly inhibited the effects of the orthostatic stress of quiet sitting on the cardiovascular system of adult women (Madhavan et al. 2006). Thus, applying resistive vibration exercise with a higher frequency may have led to alternative results.

Due to the relatively small group sample size in this study, statements must be made carefully. Combining the present results of a decreased capacitance and the absence of a resistive vibration exercise effect after 52 days of bed rest, we propose that the bed rest inactivity itself is not the main stimulus for adaptations of the venous vascular system. There ought to be an alternative or additional specific factor during bed rest deconditioning which is responsible for venous changes, e.g. microgravity.

In conclusion, this study demonstrates that 52 days of bed rest deconditioning results in a significantly decreased popliteal vein capacitance, while popliteal vein diameter and compliance did not change. Furthermore, the use of resistive vibration exercise $(19-25 \mathrm{~Hz})$ during bed rest deconditioning has no influence, and therefore no protective effect on long-term bed rest responses in venous vascular dimension and function. During bed rest deconditioning, adaptations in the venous vascular system are triggered by different stimuli than in the arterial vascular system.

Acknowledgments We wish to thank the study participants, and Bregina Kersten for ultrasound analysis. The Berlin Bed Rest study was supported by grant 14431/02/NL/SH2 from the European Space Agency. Furthermore, it was supported by Charité-University Medicine Berlin (Campus Benjamin Franklin), DLR (German 
Aerospace), the Institute for Fundamental and Clinical Movement Sciences, MSD Sharp \& Dohme, Lilly Germany, Servier Germany, Hoffmann-LaRoche, Siemens, Novartis, and Seca. The study was investigator-initiated and all data were collected, stored and interpreted by the investigators without external interference. N.T.L.v.D. is financially supported by The Netherlands Heart Foundation (NHS No 2005B113); D.H.J.T. is financially supported by The Netherlands Organization for Scientific Research (NWO-grant 82507010).

Open Access This article is distributed under the terms of the Creative Commons Attribution Noncommercial License which permits any noncommercial use, distribution, and reproduction in any medium, provided the original author(s) and source are credited.

\section{References}

Akima H, Ushiyama J, Kubo J, Tonosaki S, Itoh M, Kawakami Y et al (2003) Resistance training during unweighting maintains muscle size and function in human calf. Med Sci Sports Exerc 35:655662. doi:10.1249/01.MSS.0000058367.66796.35

Arbeille P, Fomina G, Roumy J, Alferova I, Tobal N, Herault S (2001) Adaptation of the left heart, cerebral and femoral arteries, and jugular and femoral veins during short- and long-term headdown tilt and spaceflights. Eur J Appl Physiol 86:157-168. doi: $10.1007 / \mathrm{s} 004210100473$

Arbeille P, Herault S, Fomina G, Roumy J, Alferova I, Gharib C (1999) Influences of thigh cuffs on the cardiovascular system during 7-day head-down bed rest. J Appl Physiol 87:21682176

Belin de Chantemele E, Pascaud L, Custaud MA, Capri A, Louisy F, Ferretti $\mathrm{G}$ et al (2004) Calf venous volume during stand-test after a 90-day bed-rest study with or without exercise countermeasure. J Physiol 561:611-622. doi:10.1113/jphysiol.2004.069468

Bleeker MW, De Groot PC, Pawelczyk JA, Hopman MT, Levine BD (2004) Effects of 18 days of bed rest on leg and arm venous properties. J Appl Physiol 96:840-847. doi:10.1152/japplphysiol. 00835.2003

Bleeker MW, De Groot PC, Poelkens F, Rongen GA, Smits P, Hopman MT (2005a) Vascular adaptation to $4 \mathrm{wk}$ of deconditioning by unilateral lower limb suspension. Am J Physiol Heart Circ Physiol 288:H1747-H1755. doi:10.1152/ajpheart.00966. 2004

Bleeker MW, De Groot PC, Rongen GA, Rittweger J, Felsenberg D, Smits P, et al. (2005b) Vascular adaptation to deconditioning and the effect of an exercise countermeasure: results of the Berlin Bed Rest study. J Appl Physiol

Bonde-Petersen F, Suzuki Y, Kawakubo K, Gunji A (1994) Effect of 20 days bed rest upon peripheral capillary filtration rate, venous compliance and blood flow in arms and legs. Acta Physiol Scand Suppl 616:65-69

Brakkee AJ, Kuiper JP (1982) Plethysmographic measurement of venous flow resistance in man. Vasa 11:166-167

Buckey JC, Lane LD, Plath G, Gaffney FA, Baisch F, Blomqvist CG (1992) Effects of head-down tilt for 10 days on the compliance of the leg. Acta Physiol Scand Suppl 604:53-59

Buckey JC, Peshock RM, Blomqvist CG (1988) Deep venous contribution to hydrostatic blood volume change in the human leg. Am J Cardiol 62:449-453. doi:10.1016/0002-9149(88) 90976-9

Christ F, Gamble J, Baranov V, Kotov A, Chouker A, Thiel M et al (2001) Changes in microvascular fluid filtration capacity during 120 days of 6 degrees head-down tilt. J Appl Physiol 91:25172522
Convertino VA (1996) Exercise as a countermeasure for physiological adaptation to prolonged spaceflight. Med Sci Sports Exerc 28:999-1014. doi:10.1097/00005768-199608000-00010

Convertino VA, Doerr DF, Flores JF, Hoffler GW, Buchanan P (1988) Leg size and muscle functions associated with leg compliance. J Appl Physiol 64:1017-1021

Convertino VA, Doerr DF, Mathes KL, Stein SL, Buchanan P (1989) Changes in volume, muscle compartment, and compliance of the lower extremities in man following 30 days of exposure to simulated microgravity. Aviat Space Environ Med 60:653-658

De Groot PC, Bleeker MW, Hopman MT (2005) Ultrasound: a reproducible method to measure conduit vein compliance. J Appl Physiol 98:1878-1883. doi:10.1152/japplphysiol.01166.2004

De Groot PC, Bleeker MW, van Kuppevelt DH, van der Woude LH, Hopman MT (2006) Rapid and extensive arterial adaptations after spinal cord injury. Arch Phys Med Rehabil 87:688-696. doi:10.1016/j.apmr.2006.01.022

Fomina GA, Kotovskaia AR (2005) Shifts in human venous hemodynamics in long-term space flight. Aviakosm Ekolog Med 39:25-30

Frieden RA, Ahn JH, Pineda HD, Minutoli F, Whelan E (1987) Venous plethysmography values in patients with spinal cord injury. Arch Phys Med Rehabil 68:427-429

Hopman MT, Nommensen E, van Asten WN, Oeseburg B, Binkhorst RA (1994) Properties of the venous vascular system in the lower extremities of individuals with paraplegia. Paraplegia 32:810 816

Jeanneret C, Labs KH, Aschwanden M, Gehrig A, Jager KA (2000) Venous cross-sectional area: measured or calculated? Ultraschall Med 21:16-19. doi:10.1055/s-2000-8925

Kerschan-Schindl K, Grampp S, Henk C, Resch H, Preisinger E, Fialka-Moser V et al (2001) Whole-body vibration exercise leads to alterations in muscle blood volume. Clin Physiol 21:377-382. doi:10.1046/j.1365-2281.2001.00335.x

Kubo K, Akima H, Ushiyama J, Tabata I, Fukuoka H, Kanehisa H et al (2004) Effects of resistance training during bed rest on the viscoelastic properties of tendon structures in the lower limb. Scand J Med Sci Sports 14:296-302. doi:10.1046/j.1600-0838. 2003.00368.x

Louisy F, Schroiff P, Guell A (1997) Changes in leg vein filling and emptying characteristics and leg volumes during long-term headdown bed rest. J Appl Physiol 82:1726-1733

Madhavan G, Stewart JM, McLeod KJ (2006) Cardiovascular systemic regulation by plantar surface stimulation. Biomed Instrum Technol 40:78-84

Melchior FM, Fortney SM (1993) Orthostatic intolerance during a 13-day bed rest does not result from increased leg compliance. J Appl Physiol 74:286-292

Miyachi M, Tanaka H, Yamamoto K, Yoshioka A, Takahashi K, Onodera S (2001) Effects of one-legged endurance training on femoral arterial and venous size in healthy humans. J Appl Physiol 90:2439-2444

Monahan KD, Dinenno FA, Seals DR, Halliwill JR (2001) Smaller age-associated reductions in leg venous compliance in endurance exercise-trained men. Am J Physiol Heart Circ Physiol 281:H1267-H1273

Mulder ER, Stegeman DF, Gerrits KH, Paalman MI, Rittweger J, Felsenberg D et al (2006) Strength, size and activation of knee extensors followed during 8 weeks of horizontal bed rest and the influence of a countermeasure. Eur J Appl Physiol 97:706-715. doi:10.1007/s00421-006-0241-6

Pointel JP, Gin H, Drouin P, Vernhes G, Debry G (1981) Venous plethysmography: measuring techniques and normal values. Angiology 32:145-154. doi:10.1177/000331978103200301

Rittweger J, Belavy D, Hunek P, Gast U, Boerst H, Feilcke B et al (2006) Highly demanding resistive vibration exercise program is 
tolerated during 56 days of strict bed-rest. Int J Sports Med 27:553-559. doi:10.1055/s-2005-872903

Rittweger J, Beller G, Felsenberg D (2000) Acute physiological effects of exhaustive whole-body vibration exercise in man. Clin Physiol 20:134-142. doi:10.1046/j.1365-2281.2000.00238.x

Rothe CF (1986) Physiology of venous return. An unappreciated boost to the heart. Arch Intern Med 146:977-982. doi: 10.1001/archinte.146.5.977

Van Langen H (2003) A three-parameter model for the venous pressure volume relation of the lower leg. Phlebology 18:83-91. doi: $10.1258 / 026835503321895398$

Watenpaugh DE, Buckey JC, Lane LD, Gaffney FA, Levine BD, Moore WE et al (2001) Effects of spaceflight on human calf hemodynamics. J Appl Physiol 90:1552-1558
Wecht JM, de Meersman RE, Weir JP, Bauman WA, Grimm DR (2000) Effects of autonomic disruption and inactivity on venous vascular function. Am J Physiol Heart Circ Physiol 278:H515H520

Wilkinson IB, Webb DJ (2001) Venous occlusion plethysmography in cardiovascular research: methodology and clinical applications. Br J Clin Pharmacol 52:631-646. doi:10.1046/j.0306-5251. 2001.01495.x

Xiao X, Grenon SM, Kim C, Sheynberg N, Hurwitz S, Williams GH et al (2005) Bed rest effects on human calf hemodynamics and orthostatic intolerance: a model-based analysis. Aviat Space Environ Med 76:1037-1045 